\title{
PERSEPSI PENGURUS PESANTREN TRADISIONAL TERHADAP HUKUM MEROKOK DAN DAMPAK MEROKOK DENGAN INTENSI BERHENTI MEROKOK DI KABUPATEN PIDIE JAYA
}

\author{
PERCEPTION OF TRADITIONAL ISLAMIC BOARDING SCHOOL \\ MANAGEMENT ON LAW AND SMOKING IMPACT WITH SMOKING STOP \\ INTENSION IN PIDIE JAYA DISTRICT
}

\author{
Razali $^{1^{*}}$, Fahmi Ichwansyah ${ }^{2}$, Ali Abubakar ${ }^{1}$ \\ Program Studi Magister Kesehatan Masyarakat, Fakultas Kesehatan Masyarakat, \\ Universitas Muhammadiyah Aceh \\ Jl. Kampus Muhammadiyah, Batoh Banda Aceh - Indonesia \\ ${ }^{2}$ Balai Penelitian dan Pengembangan Kesehatan Aceh \\ J1.Bandara Sultan Iskandar Muda Lr. Tgk. Dilangga Gp. Bada, Ingin Jaya, Aceh Besar. \\ *email: rajaly982@gmail.com
}

\begin{abstract}
ABSTRAK
Aceh merupakan salah satu provinsi dengan persentase perokok yang sangat tinggi yaitu $29,3 \%$. Banyak penelitian yang telah dilakukan untuk mengkaji faktor yang mempengaruhi perilaku merokok namun belum banyak yang mengkaji mengenai intensi berhenti merokok terutama pada kalangan pesantren. Penelitian ini akan mengkaji persepsi terhadap hukum dan dampak merokok dengan intesi berhenti merokok pada pengurus pesantren tradisional di Kabupaten Pidie Jaya. Jenis penelitian analitik dengan desain potong lintang. Populasi dalam penelitian pengurus yang menetap di pesantren tradisional. Sampel penelitian sebanyak 96 orang dengan menggunakan teknik proporsional random sampling. Analisis data dengan menggunakan regresi linear. Hasil penelitian didapatkan ada pengaruh persepsi terhadap dampak merokok terhadap intensi berhenti merokok $(p=0,002)$, dan tidak ada pengaruh persepsi hukum merokok terhadap intensi berhenti merokok. Faktor yang internal yang berpengaruh terhadap intensi berhenti merokok adalah lama merokok $(p=0,001)$, jumlah rokok $(p=0,009)$, pendidikan $(p=0,006)$ dan lingkungan $(p=0,001)$. Faktor eksternal meliputi iklan dampak merokok $(p=0,001)$ berpengaruh terhadap intensi berhenti merokok. Kesimpulan dari penelitian ini secara tidak langsung faktor internal melalui persepsi terhadap dampak merokok mempunyai pengaruh terhadap intensi berhenti merokok. Namun tidak mempunyai pengaruh jika melalui persepsi terhadap hukum. Kepada Dinas Kesehatan Kabupaten Pidie Jaya agar dapat meningkatkan kampanye tentang bahaya dari rokok serta meningkatkan konseling kepada perokok aktif yang ingin berhenti merokok. Perlu peningkatan pengawasan terhadap tempat-tempat yang menjadi kawasan tanpa rokok sehingga dapat meningkatkan keinginan berhenti merokok.
\end{abstract}

Kata Kunci: hukum merokok, intensi merokok, berhenti merokok

\begin{abstract}
Aceh is one of the provinces with a very high percentage of smokers at 29.3\%. Much research has been done to examine the factors that influence smoking behavior, but not many have examined the intentions of quitting smoking, especially among pesantren. This study will examine perceptions of the law and the impact of smoking with the cessation of smoking cessation at traditional islamic boarding school administrators in Pidie Jaya Regency. This type of analytic research with cross sectional study design. The population in the study of administrators who settled in Traditional Pesantren. The research sample of 96 people using proportional random sampling technique. Data analysis using a linear regression with the stata program. The effect of perception on the impact of smoking on the intention to stop smoking $(p=0.002)$, there was no effect of the
\end{abstract}


perception of smoking law on the intention to stop smoking. Internal factors that influence the intention to stop smoking are smoking duration $(p=0.001)$, number of cigarettes $(p=0.009)$, education $(p=0.006)$ and environment $(p=0.001)$. External factors include advertising the impact of smoking $(p=0.001)$ effect on the intention to stop smoking. The conclusion of this study indirectly internal factors through the perception of the effects of smoking have an influence on the intention to stop smoking. But it has no influence if through perception of the law. To the Pidie Jaya District Health Office in order to increase the campaign about the dangers of smoking and improve counseling for active smokers who want to quit smoking. Need to increase supervision of places that are areas without smoking so as to increase the desire to stop smoking.

Keywords: smoking law, smoking intention, stop smoking

\section{PENDAHULUAN}

Merokok dapat meningkatkan angka kematian, menurut WHO pada tahun 2015 terdapat 6,4 juta orang meninggal akibat rokok, dalam satu jam 46 orang meninggal akibat rokok, dengan total 1.127 orang meninggal dalam sehari akibat rokok. Selain itu rokok menyebabkan risiko terbesar kedua kematian dini dan kecacatan setelah tekanan darah tinggi. ${ }^{1}$ Penggunaan tembakau, terutama rokok merupakan penyebab utama penyakit dan kematian yang dapat dicegah di negara maju. ${ }^{2}$ Hampir semua penggunaan tembakau dimulai pada masa muda dan dewasa muda. $^{3}$

Penggunaan tembakau adalah bagian kehidupan sehari-hari bagi orang di Indonesia, kenyataan ini menempatkan negara Indonesia sebagai konsumen tembakau terbesar ketiga di dunia setelah India dan China. ${ }^{4}$ Sebagian besar perokok ingin berhenti dan telah mencoba untuk berhenti merokok. Akan tetapi sebagian besar keinginan tersebut gagal karena pengaruh kualitas adiktif yang kuat dari nikotin dan isyarat sensorik dan perilaku non-nikotin. $^{5}$

Proporsi penduduk Indonesia usia 15 tahun ke atas yang merokok pada tahun 2018 adalah 33,8\%. ${ }^{6}$ Aceh merupakan salah satu provinsi dengan prevalensi perokoknya terbanyak di Indonesia. Angka perokok di Provinsi Aceh sama dengan prevalensi perokok nasional. Menurut Riskesdas Provinsi Aceh (2013), proporsi perokok di provinsi Aceh adalah 29,3\% terdiri dari perokok aktif sebanyak 25,0\%, perokok kadang-kadang 4,3\%, sedangkan mantan perokok 2,5\% dan bukan perokok 68,2\%. Proporsi perokok di Kabupaten Pidie Jaya adalah $28,3 \%$, terdiri dari perokok setiap hari $21,9 \%$ dan perokok kadang-kadang $6,4 \%{ }^{7}$

Faktor- faktor yang mempengaruhi berhenti merokok antara lain: edukasi yang tinggi mengenai rokok, ${ }^{8}$ kesadaran mengenai kerugian merokok, mendukung kebijakan bebas asap rokok di dalam rumah, anjuran atau nasehat dari dokter atau petugas kesehatan, peringatan mengenai bahaya merokok, tingginya harga 
rokok dan emosi negatif yang ada pada seseorang. ${ }^{9}$ Merokok adalah hal yang bisa dikatakan relatif baru, karena belum dikenal pada zaman Nabi Muhammad SAW, sehingga muncul beragam opini dalam suatu non legislasi, baik ulama secara langsung atau organisasi keagamaan yang sering digunakan sebagai referensi untuk masyarakat umum. ${ }^{10}$

Proporsi perokok di Kabupaten Pidie Jaya cukup tinggi 28,3\%. Masalah hukum rokok masih menjadi perdebatan di kalangan ulama. Ada yang menyatakan haram, ada juga yang menyatakan makruh. Namun dari segi kesehatan dampak merokok dapat menyebabkan berbagai masalah kesehatan seperti yang tertera di bungkus rokok yaitu penyakit jantung, stroke, impotensi dan gangguan pada janin. Penelitian ini bertujuan untuk mengetahui persepsi pengurus pesantren tradisional terhadap hukum merokok dan dampak merokok dengan intensi berhenti merokok di Kabupaten Pidie Jaya.

\section{METODE PENELITIAN}

Penelitian ini merupakan penelitian kuantitatif dengan desain cross-sectional study. Lokasi penelitian dilakukan di Pesantren Tradisional Kabupaten Pidie Jaya. Penelitian dilakukan dari tanggal 03 sampai dengan 10 Agustus 2017. Populasi adalah seluruh pengurus yang menetap di pesantren tradisional sebanyak 806 orang pada 38 Pesantren. Sampel penelitian sebanyak 96 orang, pengambilan sampel dengan menggunakan teknik stratified random sampling yaitu pengambilan sampel melalui proses pembagian populasi kedalam strata (pesantren), kemudian sampel dipilih secara acak sederhana dari setiap pesantren sehingga sampel dapat mewakili setiap pesantren, dengan kriteria sampel adalah perokok aktif, pengurus/ pengajar di pesantren, dan tinggal di pesantren. Pengumpulan data dilakukan dengan wawancara dengan mengggunakan kuesioner yang sudah dilakukan uji validitas. Data dianalisis dengan menggunakan regresi regresi linear.

\section{HASIL PENELITIAN}

Hasil analisis mengenai hubungan persepsi hukum merokok, perssepsi dampak merokok, lama merokok, jumlah rokok yang dihisap, pengetahuan, pendidikan, sosial ekonomi, lingkungan, iklan rokok dan sarana berhenti merokok dengan intensi berhenti merokok dapat dilihat pada tabel 1 .

Hasil penelitian pada tabel di atas menunjukkan faktor yang berhubungan dengan intensi berhenti merokok adalah lama merokok $(\mathrm{OR}=4,5 ; p=0,001)$, jumlah rokok $(\mathrm{OR}=2,2 ; \quad p=0,001)$, pengetahuan $(\mathrm{OR}=3,2 ; \quad p=0,008), \quad$ sosial ekonomi $(\mathrm{OR}=4,4 ; p=0,001)$, lingkungan $(\mathrm{OR}=2,9$; $p=0,009)$ dan iklan dampak merokok $(\mathrm{OR}=4,7 ; p=0,001)$. 
Tabel 1. Analisis faktor yang berhubungan dengan intensi berhenti merokok

\begin{tabular}{|c|c|c|c|c|c|c|c|}
\hline $\begin{array}{l}\text { No } \\
1 .\end{array}$ & $\begin{array}{c}\text { Variabel } \\
\text { Persepsi Hukum Merokok }\end{array}$ & \multicolumn{2}{|c|}{ Tidak ada } & \multicolumn{2}{|c|}{ Ada } & OR $(95 \% \mathrm{CI})$ & $p$ \\
\hline & Negatif & 35 & 55,6 & 28 & 44,4 & $1,6(0,72-3,83)$ & 0,23 \\
\hline & Positif & 15 & 42,8 & 20 & 57,2 & & \\
\hline \multirow[t]{3}{*}{2.} & Persepsi Dampak Merokok & & & & & & \\
\hline & Negatif & 28 & 58,3 & 20 & 41,7 & $1,7(0,80-3,96)$ & 0,15 \\
\hline & Positif & 22 & 44,0 & 28 & 56,0 & & \\
\hline \multirow[t]{3}{*}{3.} & Lama Merokok & & & & & & \\
\hline & Perokok lama & 39 & 65,0 & 21 & 35,0 & $4,5(1,89-10,98)$ & $0,001 *$ \\
\hline & Perokok baru & 11 & 28,9 & 27 & 71,1 & & \\
\hline \multirow[t]{3}{*}{4.} & Jumlah Rokok & & & & & & \\
\hline & Perokok berat & 43 & 62,3 & 26 & 37,6 & 2,2 (1.39- 3.72-) & $0,001 *$ \\
\hline & Perokok ringan & 7 & 24,1 & 22 & 75,9 & & \\
\hline \multirow[t]{3}{*}{5.} & Pengetahuan & & & & & & \\
\hline & Kurang & 39 & 60,9 & 25 & 39,1 & $3,2(1,35-7.83)$ & $0,008^{*}$ \\
\hline & Baik & 11 & 32,5 & 23 & 67,5 & & \\
\hline \multirow[t]{3}{*}{6.} & Pendidikan & & & & & & \\
\hline & Dasar & 36 & 48,6 & 38 & 51,4 & $0,8(0,51-1.31)$ & 0,411 \\
\hline & Tinggi & 14 & 58,3 & 10 & 41,7 & & \\
\hline \multirow[t]{3}{*}{7.} & Sosial ekonomi & & & & & & \\
\hline & Di bawah UMP & 32 & 51,6 & 30 & 48,4 & $4.4(1.78-11.15)$ & $0,001 *$ \\
\hline & Sesuai UMP & 18 & 50,0 & 18 & 50,0 & & \\
\hline \multirow[t]{3}{*}{8.} & Lingkungan & & & & & & \\
\hline & Tidak mendukung & 31 & 64,6 & 17 & 35,4 & $2,9(1.3-6.77)$ & $0,009 *$ \\
\hline & Mendukung & 19 & 38,0 & 31 & 62,0 & & \\
\hline \multirow[t]{3}{*}{9.} & Iklan Dampak Merokok & & & & & & \\
\hline & Tidak berpengaruh & 31 & 64,5 & 17 & 35,5 & $4.7(1.83-12.04)$ & $0,001 *$ \\
\hline & Berpengaruh & 19 & 38,0 & 31 & 62,0 & & \\
\hline \multirow[t]{3}{*}{10.} & Sarana Berhenti Merokok & & & & & & \\
\hline & Tidak ada & 35 & 31,2 & 11 & 68,8 & $0,3(0.11 \quad 1.17)$ & 0,09 \\
\hline & Ada & 45 & 54,8 & 37 & 45,2 & & \\
\hline
\end{tabular}

Variabel yang memiliki hubungan dalam analisis multivariat. Hasil analisis dalam analisis bivariat akan diikutsertakan dapat dilihat pada tabel berikut: 
Tabel 2. Analisis faktor yang paling berhubungan dengan intensi berhenti merokok

\begin{tabular}{|c|c|c|}
\hline Variabel & Coef. & $p$ \\
\hline Lama merokok & -.227 & 0.210 \\
\hline Jumlah merokok & -.033 & 0.012 \\
\hline Pengetahuan & 0,26 & 0.760 \\
\hline Sosial ekonomi & 1,74 & 0.031 \\
\hline Lingkungan & 0,426 & 0.023 \\
\hline Iklan dampak merokok & 0,78 & 0.022 \\
\hline
\end{tabular}

Hasil analisis multivariat merupakan faktor yang berpengaruh
menunjukkan variabel yang paling terhadap berhenti merokok. ${ }^{12}$ berhubungan dengan intensi berhenti Hasil penelitian menunjukkan ada merokok adalah jumlah rokok yang dihisap $(p=0,012)$ dengan nilai koefesien negatif ,033 artinya intensi berhenti merokok tidak ada pada perokok berat sebesar $33 \%$.

\section{PEMBAHASAN}

Hasil penelitian menunjukkan ada hubungan antara lama merokok dengan intensi berhenti merokok $(\mathrm{OR}=4,5$; $p=0,001$, nilai odd ratio dapat disimpulkan pada responden yang sudah lama merokok cenderung tidak ada intensi berhenti merokok hampir 5 kali lebih besar dibandingkan perokok baru. Faktor penyulit seseorang berhenti merokok yaitu efek psikoaktif nikotin yang sangat kuat yakni 5-10 kali lebih kuat dari kokain dan morfin, reseptor pada otak yang menerima nikotin akan melepaskan dopamin yang memberikan rasa nyaman sementara. ${ }^{11}$ Faktor kecanduan dan lingkungan hubungan antara jumlah rokok yang dihisap dengan intensi berhenti merokok $(\mathrm{OR}=2,2$; $p=0,001$ ), dapat disimpulkan tidak ada keinginan berhenti merokok pada perokok berat 2,1 lebih besar dibandingkan dengan responden perokok ringan. Meskipun jumlah rokok yang dihisap perharinya sama namun dosis nikotin yang dihisap perharinya dapat berbeda-beda antara individu dan pada akhirnya menimbulkan efek nikotin yang berbeda pula. ${ }^{13}$ Berbeda dengan penelitian lain yang menyebutkan tidak ada hubungan antara lama merokok dan jumlah rokok dengan keberhasilan berhenti merokok. ${ }^{14}$

$$
\text { Terdapat hubungan antara }
$$
pengetahuan $(\mathrm{OR}=3,2 ; \quad p=0,008)$ dengan intensi berhenti merokok, dapat diartikan responden berpengetahuan kurang cenderung tidak ada intensi berhenti merokok 3 kali lebih besar dibandingkan 
responden pengetahuan baik. Penelitian lain menyebutkan kurangnya pengetahuan tentang dampak rokok merupakan salah satu faktor penghambat motivasi berhenti merokok. $^{15}$ Kurangnya pengetahuan mengenai cara menghentikan kecanduan nikotin membuat sebagian besar perokok gagal menghentikan kebiasaan merokok. ${ }^{11}$

Hasil penelitian menunjukkan ada hubungan antara lingkungan $(\mathrm{OR}=2,9$; $p=0,009$ ) dengan intensi berhenti merokok, dimana responden yang tidak ada dukungan dari lingkungan untuk berhenti merokok cenderung tidak ada intensi berhenti merokok 3 kali lebih besar dibandingkan dengan responden dengan lingkungan mendukung. Dukungan yang diterima akan memiliki arti bila dukungan itu bermanfaat dan sesuai dengan situasi yang ada. Semakin tinggi dukungan sosial terhadap peserta didik maka semakin tinggi pula motivasi berhenti merokok. ${ }^{16}$ Salah satu kesulitan terbesar untuk berhenti merokok dikarenakan sebagian besar mempunyai lingkungan yang juga seorang perokok. ${ }^{17}$

Hasil penelitian menunjukkan terdapat hubungan antara iklan dampak merokok $(\mathrm{OR}=4,7 ; p=0,001)$ dengan intensi berhenti merokok. Penelitian sebelumnya menunjukkan iklan dampak rokok dalam hubungannya dengan pembentukan dan perubahan sikap dimana sikap responden 55,0\% tinggi dan sangat tinggi. $^{18}$ Pesan pada bungkus rokok menggambarkan efek kesehatan negatif untuk perokok diidentifikasi sebagai yang paling memotivasi berhenti merokok, diikuti oleh label yang menggambarkan efek kesehatan negatif kepada orang lain. ${ }^{19}$ Pesan iklan tentang peringatan bahaya merokok berpengaruh terhadap sikap untuk berhenti merokok. ${ }^{20}$

Melihat besarnya risiko perilaku merokok, pemerintah Indonesia berupaya untuk menekan semakin tingginya angka prevalensi merokok pada usia muda, dengan mengeluarkan aturan mengenai pengamanan bahan yang mengandung zat adiktif berupa produk tembakau bagi kesehatan. Salah satu isinya adalah seluruh rokok yang beredar di Indonesia harus menyertakan peringatan bahaya rokok, disertai gambar menyeramkan akibat merokok pada bungkus rokok. ${ }^{21}$ Peringatan kesehatan dengan ilustrasi gambar yang menonjol dapat meningkatkan perhatian, kesadaran dan pemahaman serta meningkatkan ketakutan. Ilustrasi mampu menggambarkan makna kompleks dan besarnya penderitaan, menakutkan dan juga menjijikkan yang merupakan bahaya dari perilaku merokok. ${ }^{22}$

Dari hasil analisis didapatkan tidak terdapat pengaruh persepsi hukum merokok terhadap intensi berhenti merokok ( $p 0,23)$. Kecenderungan tidak ada intensi berhenti merokok pada responden dengan persepsi hukum merokok negatif hampir 2 kali lebih 
besar dibandingkan dengan responden persepsi positif $(\mathrm{OR}=1,6)$. Ulama sepakat mengenai segala sesuatu yang membawa mudarat adalah haram. Akan tetapi yang menjadi persoalan adalah apakah merokok itu membawa mudarat yang besar atau relatif kecil, dan terdapat manfaat atau tidak bagi manusia. Tercetus persepsi yang berbeda dalam meneliti dan mencermati substansi rokok dari aspek kemaslahatan dan kemafsadatan. Perbedaan persepsi ini merupakan pendapat mengenai hukum merokok dengan berbagai argumennya. Dasar para ulama menetapkan tentang merokok mengacu pada Alquran Surat AlBaqarah ayat 195 "Dan janganlah kamu menjatuhkan dirimu kedalam kebinasaan, dan berbuat baiklah, karena sesungguhnya Allah menyukai orang-orang yang berbuat baik (Q.S.Al-Baqarah :195). ${ }^{23}$

Hasil penelitian menunjukkan persepsi terhadap dampak merokok juga tidak berhubungan dengan intensi berhenti merokok $(p 0,15)$. Kecenderungan tidak ada intensi berhenti merokok pada responden dengan persepsi dampak merokok negatif hampir 2 kali lebih besar dibandingkan dengan responden persepsi dampak merokok positif $(\mathrm{OR}=1,7)$. Keinginan berhenti merokok yang sering dijumpai adalah berkaitan dengan masalah kesehatan pribadi. Hal ini diperoleh dari sepertiga orang yang berhenti merokok dan seperempat dari perokok. Pemicu umum setidaknya (label peringatan, harga rokok), didukung oleh 1 dari 10 perokok yang berhenti dan 1 di 20 perokok. $^{24}$

Penelitian sebelumnya menyebutkan ada hubungan antara sikap terhadap dampak merokok dengan niat berhenti merokok. ${ }^{25}$ Tidak semua perokok yang memiliki persepsi positif terhadap alasan berhenti merokok tersebut dapat berhasil berhenti merokok dengan mudah. Penelitian lain juga menyebutkan ada hubungan yang signifikan antara nilai dan persepsi dengan motivasi berhenti merokok. ${ }^{26-27}$

\section{KESIMPULAN}

Kesimpulan penelitian ini adalah persepsi hukum merokok dan persepsi terhadap dampak merokok tidak berhubungan dengan intensi berhenti merokok. Intensi berhenti merokok semakin rendah pada perokok berat.

\section{SARAN}

Kepada Dinas Kesehatan Kabupaten Pidie Jaya agar dapat meningkatkan kampanye tentang bahaya dari rokok serta meningkatkan konseling kepada perokok aktif yang ingin berhenti merokok. Kepada pengurus pesantren agar dapat menerapkan kawasan tanpa rokok (KTR) di lingkungan pesantren.

\section{KONTRIBUSI PENULIS}

Kontribusi penulis pada artikel ini yaitu, $\mathrm{R}$ sebagai kontributor utama berkontribusi terhadap pengumpulan data, 
merangcang isi artikel dan bertanggung jawab terhadap isi artikel. FI dan AA sebagai kontributor anggota berkontribusi dalam membantu bagian analisa data dan metode serta perbaikan bahasa dalam artikel

\section{UCAPAN TERIMA KASIH}

Kepada Prof. Asnawi Abdullah, Ph. D dan Bapak Dr. Nizam Ismail, S. Sos, MPH yang memberi masukan dalam penulisan akhir, dan juga Kepada Pimpinan Pesantren Tradisional Kabupaten Pidie Jaya sebagai tempat pelaksanaan penelitian.

\section{DAFTAR PUSTAKA}

1. Bianca Jeanne. Prevalensi Konsumsi Rokok Pria Usia 18-64 Tahun dengan Hipertensi di Desa Susut, Kabupaten Bangli Bali Tahun 2014. Intisari Sains Medis. 2016;6(1):16-22. https://isainsmedis.id/index.php/ism/art icle/viewFile/15/15.

2. Thangadurai Maheswaran, Shanmugam Mohanapriya, Nalliapan Ganapathy, Vadive Ilayaraja, Janarghanam Dineshshankar, Thukanayakanpalayam Ragunathan Yoithapprabhunath et al. Attitudes, practices, and perceived barriers in smoking cessation among the dental surgeons: A pilot study. $J$ Indian Acad Dent Spec Res. 2017;4(2). doi:10.4103/jiadsr.jiadsr_21_17

3. Ahmed Jamal, Andrea Gentzke, S. Sean Hu, Karen A. Cullen, Benjamin J. Apelberg, David M. Homa et al. Tobacco use among middle and high school students-United States, 20112016. Morb Mortal Wkly Rep. 2017;66(23):603-597.

https://www.cdc.gov/mmwr/volumes/6 6/wr/mm6623a1.htm.

4. Teuku Tahlil, John Coveney, Richard J Woodman PRW. Exploring recommendations for an effective smoking prevention program for Indonesian adolescents. Asian Pacific $J$ Cancer Prev. 2013;14(2):865-871. https://www.researchgate.net/publicatio n/236456552_Exploring_Recommenda tions_for_an_Effective_Smoking_Prev ention_Program_for_Indonesian_Adole scents.

5. Polosa R, Caponnetto P, Cibella F LHJ. Quit and smoking reduction rates in vape shop consumers: a prospective 12-month survey. Int J Environ Res Public Health. 2015;12(4):3428-3438. doi:10.3390/ijerph120403428

6. Indonesia KKR. Hasil Utama Riskesdas 2018. Jakarta; 2018. https://www.kemkes.go.id/resources/do wnload/info-terkini/hasil-riskesdas2018.pdf.

7. Kementerian Kesehatan RI BLK. Riskesdas Provonsi Aceh Tahun 2013. Jakarta; 2013. https://www.pusat2.litbang.kemkes.go.i d/wp-content/uploads/2018/03/PokokPokok-Hasil-Riskesdas-Prov-Aceh.pdf.

8. Gauri G. Dhumal, Mangesh S. Pednekar , Prakash C. Gupta, Genevieve Sansone, ACK Quah, M Bansal-Travers et al. Quit history, intentions to quit, and reasons for considering quitting among tobacco users in India: Findings from the Wave 1 TCP India Survey. Indian J Cancer. 2014;51(1):39-45. doi:10.4103/0019509X.147467

9. Anafrin Yugistyowati R. Pengaruh Terapi Spiritual Emotional Freedom Technique (SEFT) Terhadap Motivasi Berhenti Merokok Pada Remaja. $J$ Keperawatan Respati Yogyakarta. 2018;5:34-38.

http://nursingjurnal.respati.ac.id/index. php/JKRY/article/view/284.

10. Yogyakarta. JKR. Merokok Dalam Perspektif Muhammadiyah Dan Nahdhatul Ulama. Al-Qadha J Huk Islam Dan Perundang-undangan. 2017;4(1):16-33. 
https://www.journal.iainlangsa.ac.id/in dex.php/qadha/article/download/174/11 1.

11. Sherly Natasha Indrawani, Liana Mailani NN. Intensi Berhenti Merokok: Peran Sikap Terhadap Peringatan pada bungkus Rokok dan Perceived Behavioral Control. Psikologia. J Pemikir dan Penelit Psikol. 2014;9(2):65-73.

https://jurnal.usu.ac.id/index.php/psikol ogia/article/view/8761/0.

12. Rizanna Rosemary. Antara motivasi dan tantangan berhenti merokok (studi kasus mahasiswa di Banda Aceh). J Komunikologi (Ilmu Komunikasi). 2013;10(1):9-18.

https://ejurnal.esaunggul.ac.id/index.ph $\mathrm{p} / \mathrm{Kom} / \mathrm{article} / \mathrm{view} / 1018$.

13. Nurhidayati Fawzani AT. Terapi berhenti merokok (studi kasus perokok berat). Makara, Kesehat. 2005;9(1):1524.

http://journal.ui.ac.id/index.php/health/ article/download/342/338.

14. Riska Rosita, Dwi Linna Suswardany ZA. Penentu keberhasilan berhenti merokok pada mahasiswa. J Kesehat Masy.

2012;8(1):1-9. https://journal.unnes.ac.id/nju/index.ph p/kemas/article/view/2252.

15. Kumboyono. Analisis Faktor Penghambat Motivasi Berhenti Merokok Berdasarkan Health Belief Model pada Mahasiswa Fakultas Teknik Universitas Brawijaya Malang. $J$ Keperawatan Soedirman. 2011;6(1):1-8. doi:10.20884/1.jks.2011.6.1.318

16. Whinanda Rizky Rahmasari. Hubungan Dukungan Sosial Dengan Motivasi Berhenti Merokok Pada Masa Remaja Laki-Laki Kelas Viii Smp Negeri 2 Papar Kediri Tahun Pelajaran 2014/2015. Univ Nusant PGRI Kediri. 2015:4-11.

http://simki.unpkediri.ac.id/mahasiswa/ file_artike1/2015/11.1.01.01.0314.pdf.

17. Marsiana Wibowo. Perspektif Hambatan Terhadap Kemungkinan
Remaja Berhenti Merokok. Unnes $J$ Public Heal. 2017;6(2):40-137. doi:10.15294/ujph.v6i2.13735

18. Salman Alfarisy, Agrina WL. Efektifitas pendidikan kesehatan terhadap peningkatan pengetahuan remaja tentang dampak merokok. $J$ Online Mhs Progr Stud Ilmu Keperawatan Univ Riau. 2016;1(1):19.

https://jom.unri.ac.id/index.php/JOMP SIK/article/view/3524/3419.

19. Erin L Mead, Joanna E Cohen, Caitlin E Kennedy, Joseph Gallo CAL. The role of theory-driven graphic warning labels in motivation to quit: a qualitative study on perceptions from low-income, urban smokers. $B M C$ Public Health. 2015;15(1):92.

20. Zainul Asngadah Fatmawati, Tandiyo Pradekso, Djoko Setyabudi NL. Pengaruh Terpaan Peringatan Pesan pada Iklan Rokok terhadap Sikap untuk Berhenti Merokok pada Remaja. Interak Online. 2014;8(4). https://ejournal3.undip.ac.id/index.php/ interaksi-online/article/view/6389.

21. Tantri A, 1Nur Alam Fajar FU. Hubungan Persepsi Terhadap Peringatan Bahaya Merokok Pada Kemasan Rokok Dengan Perilaku Merokok Pada Remaja Laki-Laki Di Kota Palembang. J Ilmu Kesehat Masy. 2018;9(1):74-82.

doi:10.26553/jikm.2018.9.1.74-82

22. Noor Aznidar Aldani, Said Usman TT. Pengaruh Peringatan Visual Pada Bungkus Rokok Terhadap Perilaku Merokok Pada Siswa SMA. J Ilmu Keperawatan. 2015;3(2):1-9. http://jurnal.unsyiah.ac.id/JIK/article/vi ew/6404.

23. Indis Ferizal. Mekanisme Pengujian Hukum Oleh Ulama Dalam Menetapkan Fatwa Haram Terhadap Rokok. J Huk Samudra Keadilan. 2016;11(1):55-64.

https://media.neliti.com/media/publicat ions/240362-mekanisme-pengujianhukum-oleh-ulama-dal-9ae1d283.pdf. 
24. Pek Kei Im, Ann McNeill, Mary E Thompson, Geoffrey $\mathrm{T}$ Fong, Steve Xu, Anne C K Quah, Yuan Jiang LS. Individual and interpersonal triggers to quit smoking in China: a crosssectional analysis. Tob Control. 2015;24(4):40-47.

doi:http://dx.doi.org/10.1136/tobaccoco ntrol-2014-052198

25. Dzul Akmal, Bagoes Widjanarko PN. Sikap Mempengaruhi Niat Berhenti Merokok pada Remaja SMA di Kota Bima. J Promosi Kesehat Indones. 2017;12(1):78-91.

doi:https://doi.org/10.14710/jpki.12.1.7 8-91

26. Oktarita I, Idriansari A, Muharyani
PW. Faktor-Faktor Yang Berhubungan Dengan Motivasi Berhenti Merokok Pada Sopir Angkutan Umum. $J$ Keperawatan Sriwij. 2017;4(1):14-25. https://ejournal.unsri.ac.id/index.php/jk _sriwijaya/article/download/6393/3409

27. Karina Nuur Aziizah, Ignatius Setiawan SL. Hubungan Tingkat Pengetahuan Tentang Dampak Rokok Terhadap Kesehatan Rongga Mulut dengan Tingkat Motivasi Berhenti Merokok pada Mahasiswa Universitas Kristen Maranatha. SONDE (Sound Dent. $\quad$ 2018;3(1):16-21. doi:https://doi.org/10.28932/sod.v3i1.1 774 